\title{
Adult tissue-resident stem cells-fact or fiction?
}

\author{
Deepa Bhartiya(B)
}

\begin{abstract}
Life-long tissue homeostasis of adult tissues is supposedly maintained by the resident stem cells. These stem cells are quiescent in nature and rarely divide to self-renew and give rise to tissue-specific "progenitors" (lineagerestricted and tissue-committed) which divide rapidly and differentiate into tissue-specific cell types. However, it has proved difficult to isolate these quiescent stem cells as a physical entity. Recent single-cell RNAseq studies on several adult tissues including ovary, prostate, and cardiac tissues have not been able to detect stem cells. Thus, it has been postulated that adult cells dedifferentiate to stem-like state to ensure regeneration and can be defined as cells capable to replace lost cells through mitosis. This idea challenges basic paradigm of development biology regarding plasticity that a cell enters point of no return once it initiates differentiation. The underlying reason for this dilemma is that we are putting stem cells and somatic cells together while processing for various studies. Stem cells and adult mature cell types are distinct entities; stem cells are quiescent, small in size, and with minimal organelles whereas the mature cells are metabolically active and have multiple organelles lying in abundant cytoplasm. As a result, they do not pellet down together when centrifuged at 100-350g. At this speed, mature cells get collected but stem cells remain buoyant and can be pelleted by centrifuging at $1000 \mathrm{~g}$. Thus, inability to detect stem cells in recently published single-cell RNAseq studies is because the stem cells were unknowingly discarded while processing and were never subjected to RNAseq. This needs to be kept in mind before proposing to redefine adult stem cells.
\end{abstract}

Keywords: Adult stem cells, Single-cell RNAseq, Very small embryonic-like stem cells, Cancer stem cells, Dedifferentiation, Plasticity, Pluripotent

\section{Main text}

Current omics approaches require homogenization of cells to study their contents, and it is impossible to study stem cell dynamics by these approaches since the stem cells comprise less than $1 \%$ of total cells in adult tissues. Single-cell analysis to delineate cellular transcriptome at single cell level was declared as the breakthrough of the year 2018 by the journal Science. It was postulated that single-cell RNAseq could transform the basic biology and medical research landscape in the next 10 years. However, it seems this advance has led to considerable

Correspondence: bhartiyad@nirrh.res.in

Stem Cell Biology Department, ICMR-National Institute for Research in

Reproductive Health, Jehangir Merwanji Street, Parel, Mumbai 400012, India misperceptions in the field of stem cells rather than offering clarifications. Using single-cell analysis, recent reports in leading journals have denied presence of stem cells in adult human ovarian cortex [1], murine and human prostate [2], and murine cardiac tissue [3]. It has been suggested that mature cells in adult organs like the kidneys, lungs, liver, heart, pancreas, and prostate have the ability to dedifferentiate to stem-like state and participate in regeneration. Stem cell biologists have challenged basic concepts of cell plasticity, primarily because of their inability to isolate stem cells as a physical entity and now wish to redefine adult stem cells $[4,5]$. Based on earlier reports, adult tissues are expected to harbor two populations of stem cells [6] including quiescent 
stem cells that undergo rare asymmetrical cell divisions to self-renew and give rise to slightly bigger-sized progenitors that become lineage-restricted, which divide rapidly by symmetrical cell divisions and clonal expansion before initiating differentiation into tissue-specific cell types. But Post and Clevers [7] recently proposed to redefine adult tissue stem cells based on their function to undergo mitosis to replace lost cells.

It becomes vital to appreciate the difference between stem cells and mature cells. Mature cells are bigger in size, are metabolically active, and have abundant cytoplasm holding large numbers of organelles to function normally, whereas stem cells are quiescent and much smaller in size with minimal cytoplasm and very few organelles. Stem cells remain buoyant when cell suspension (obtained after enzymatic digestion) from any tissue is spun at $100-350 \mathrm{~g}$. Somatic cells pellet down at this speed, and care is taken not to spin at higher speed; otherwise, they may get damaged and cytoplasm may burst leading to cell death. However, stem cells require higher speed of $1000 \mathrm{~g}$ to pellet down [8-13] (Fig. 1). They are not damaged by higher centrifugation speed as they have minimal cytoplasm.

As shown in Table 1, various studies [1-3] used lower speed to pellet cells, and thus, stem cells were never subjected to RNAseq during single-cell analysis leading to negative findings. Similarly, Xiao et al. [14] centrifuged at $1200 \mathrm{rpm}$ to process cells for multicolor flow cytometry experiments, discarded the stem cells unknowingly, and wrongly concluded that pancreas does not harbor stem cells. Similar technical mistake has been repeated in several published studies without realizing that they are inadvertently discarding stem cells.

We had earlier reported that pluripotent very small embryonic-like stem cells (VSELs) in bone marrow/cord blood settle down with red blood cells upon density gradient centrifugation whereas stem cells are globally studied in the buffy coat [15]. Pluripotent VSELs in the red blood cells' pellet were studied and characterized indepth [16]. Ratajczak's group from the University of Louisville, USA, reported VSELs initially in 2006, and now, > 30 independent groups have confirmed their presence [17]. These stem cells express pluripotent markers and markers specific for primordial germ cells (PGCs). Lineage and CD45- VSELs can differentiate into cells of all the 3 lineages, CD45+ HSCs, and also into germ cells [18]. Being quiescent (due to erasure of some paternally imprinted genes similar to post-migratory primordial germ cells), VSELs do not divide readily in vitro and survive both radiotherapy in mouse bone marrow [19] and chemotherapy in the testes [20, 21] and ovaries [22]. VSELs also survive in atrophied mouse uterus after bilateral ovariectomy [23]. Unlike hES/iPS cells that differentiate into their fetal counterparts, VSELs have the potential to regenerate adult tissues [24] and possibly also have a role to initiate cancers [25].

Essentially centrifuging cell suspension at $100-350 \mathrm{~g}$ allows the majority of mature cells to pellet down, and

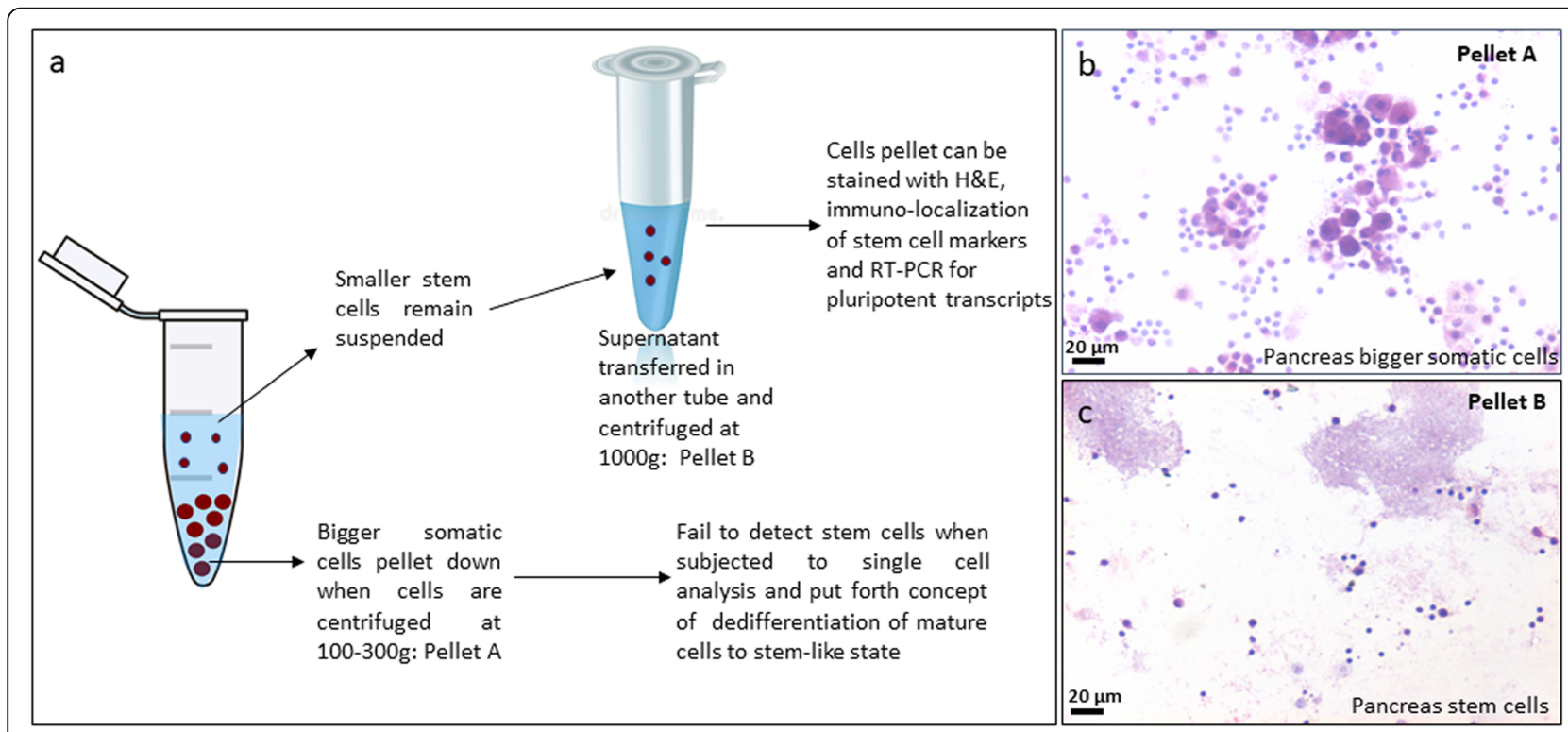

Fig. 1 Stem cells in adult pancreas. a Stem cell enrichment from adult pancreas by centrifuging at higher speed. Adult mouse pancreas was subjected to enzymatic digestion for preparing a single cell suspension. b Upon centrifugation at 250g, large numbers of cells of different sizes with abundant cytoplasm and pale stained nuclei were observed in the cell smear after H\&E staining. c On further centrifuging the supernatant at $1000 \mathrm{~g}$, putative, spherical stem cells with high nucleo-cytoplasmic ratio and darkly stained nuclei are clearly visualized. These stem cells can be further characterized by flow cytometry, immuno-localization and RT-PCR as published earlier [9]. $\mathbf{b}$ and $\mathbf{c}$ have been reproduced from our original article [9] with permission from Springer Nature 
Table 1 Centrifugation speed used to process cells for various studies

\begin{tabular}{|c|c|c|}
\hline Tissue & Speed to process cells for studies & Reference \\
\hline \multirow[t]{2}{*}{ Ovary } & Ovarian cell isolation at $300 \mathrm{~g}$ for single-cell analysis & [1] \\
\hline & Stem cells can be isolated by scraping ovary cell surface & [12] \\
\hline Prostate & Prostate cell isolation at $200 \mathrm{~g}$ for single-cell analysis & [2] \\
\hline Cardiac & Cardiac cell isolation at $100 \mathrm{~g}$ for single-cell analysis & [3] \\
\hline \multirow[t]{2}{*}{ Pancreas } & Isolation of pancreatic cells and processing for multicolor flow cytometry at $1200 \mathrm{rpm}$ & [14] \\
\hline & $\begin{array}{l}\text { Single cell suspension spun at } 1000 \mathrm{rpm} \text { and then supernatant at } 1000 \mathrm{~g} \text { helped collect VSELs } \\
\text { and pancreas stem cells (PSCs) from both pancreas and the islets }\end{array}$ & [9] \\
\hline Testes & $\begin{array}{l}\text { Single cell suspension spun at } 1000 \mathrm{rpm} \text { and then supernatant at } 1000 \mathrm{~g} \text { to collect VSELs and } \\
\text { spermatogonial stem cells (SSCs) }\end{array}$ & [11] \\
\hline Uterus & $\begin{array}{l}\text { Single cell suspension spun at } 1000 \mathrm{rpm} \text { and then supernatant at } 1000 \mathrm{~g} \text { to collect VSELs and } \\
\text { endometrial stem cells (EnSCs) }\end{array}$ & [10] \\
\hline $\begin{array}{l}\text { Pancreas, spleen, lungs, gut epithelium, } \\
\text { bone marrow, muscles }\end{array}$ & Single cell suspension spun at $1000 \mathrm{rpm}$ and then supernatant at $1000 \mathrm{~g}$ to collect stem cells & [8] \\
\hline
\end{tabular}

later centrifugation of the supernatant at $1000 \mathrm{~g}$ allows enrichment of stem cells. Using this simple and robust approach that can be easily replicated by any lab, VSELs and slightly bigger "progenitors" can be enriched in multiple adult tissues [8-13]. Appreciating and incorporating this crucial detail during processing to study stem cells will ensure their detection by single-cell analysis and will empower adult stem cell biology in normal and cancerous tissues and regenerative medicine to progress convincingly.

Similar to stem cells in adult tissues, there is still lack of clarity on the stem cells in cancer tissues (CSCs). The concept of CSCs was proposed 4 decades ago, but their identification and eradication have not been achieved as yet as was hoped initially. It was recently suggested by Clever's group that CSCs also do not necessarily have to be rare and quiescent like the adult tissue-resident stem cells [26]. Logically, CSCs are the normal tissue stem cells that start functioning abnormally (uncontrolled proliferation) rather than their normal function of remaining quiescent and functioning in a subtle manner to maintain homeostasis. Have we missed out on CSCs on similar grounds and for similar reasons like the adult stem cells? Have CSCs been discarded unknowingly by centrifuging cells at lower speeds? This remains to be studied. Despite decades of research, we still do not understand how cancer initiates. Cancer incidence is increasing in current times, and new drugs are required for therapy that avoid recurrence. Tuveson and Clevers [27] discussed cancer modeling by use of organoids obtained by 3D culture as a good alternative for screening drugs for oncotherapy. But organoids are formed by actively dividing cancer cells and may not truly mirror the CSCs that are relatively quiescent in nature and survive oncotherapy. Our group recently showed that testicular cancer was initiated in adult mice, by treating them during neonatal life with diethylstilbestrol, due to excessive self-renewal of VSELs (increased seven folds) as confirmed by flow cytometry (cells were always centrifuged at $1000 \mathrm{~g}$ to enumerate VSELs) along with their blocked differentiation due to disruption of NP95 expression [25]. This study provides first evidence that cancer results as a result of aberrant behavior of VSELs. This concept was earlier proposed by Ratajczak's group [28]. Ubiquitous expression of embryonic markers including OCT-4 and CD-133 on different types of cancers suggests that they all have a common origin from VSELs.

To conclude, wider acceptance and basic understanding of VSELs' biology in normal and cancerous tissues is much required for future translation in the field of regenerative medicine and cancer biology.

\section{Abbreviations \\ hES: Human embryonic stem cells; iPS: Induced pluripotent stem cells; VSELs: Very small embryonic-like stem cells; CSCs: Cancer stem cells; HSCs: Hematopoietic stem cells}

\section{Acknowledgements}

Acknowledge the contributions of all my students and staff to arrive at this understanding

\section{Author's contributions}

This letter is an outcome of almost two decades of research on stem cells. The author read and approved the final manuscript.

\section{Funding}

Core funding provided by Indian Council of Medical Research, Government of India, New Delhi.

\section{Availability of data and materials Not applicable}

Ethics approval and consent to participate Not applicable

Consent for publication

NIRRH accession number OTH/955/05-2020

Competing interests

The author indicated no potential conflicts of interest. 
Received: 18 September 2020 Accepted: 5 January 2021

Published online: 21 January 2021

\section{References}

1. Wagner M, Yoshihara M, Douagi I, Damdimopoulos A, Panula S, Petropoulos $S$, et al. Single-cell analysis of human ovarian cortex identifies distinct cell populations but no oogonial stem cells. Nat Commun. 2020;11:1147.

2. Karthaus WR, Hofree M, Choi D, Linton EL, Turkekul M, Bejnood A, et al. Regenerative potential of prostate luminal cells revealed by single-cell analysis. Science. 2020;368:497-505.

3. Kretzschmar K, Post Y, Bannier-Hélaouët M, Mattiotti A, Drost J, Basak O, et al. Profiling proliferative cells and their progeny in damaged murine hearts. Proc Natl Acad Sci U S A. 2018;115:E12245-54.

4. Clevers H, Watt FM. Defining adult stem cells by function, not by phenotype. Annu Rev Biochem. 2018;87:1015-27.

5. Clevers H. Stem cells. What is an adult stem cell? Science. 2015;350(6266): 1319-20.

6. Li L, Clevers H. Coexistence of quiescent and active adult stem cells in mammals. Science. 2010;327(5965):542-5.

7. Post $\mathrm{Y}, \mathrm{Clevers} \mathrm{H}$. Defining adult stem cell function at its simplest: the ability to replace lost cells through mitosis. Cell Stem Cell. 2019;25(2):174-83.

8. Bhartiya D, Mohammad SA, Guha A, Singh P, Sharma D, Kaushik A. Evolving definition of adult stem/progenitor cells. Stem Cell Rev Rep. 2019;15(3):456-8.

9. Mohammad SA, Metkari SM, Bhartiya D. Mouse pancreas stem/progenitor cells get augmented by streptozotocin and regenerate diabetic pancreas after partial pancreatectomy. Stem Cell Rev Rep. 2020;16:144-58.

10. Singh P, Bhartiya D. Pluripotent stem (VSELs) and progenitor (EnSCs) cells exist in adult mouse uterus and show cyclic changes across estrus cycle. Reprod Sci. 2020. https://doi.org/10.1007/s43032-020-00250-2.

11. Kaushik A, Bhartiya D. Additional evidence to establish existence of two stem cell populations including VSELs and SSCs in adult mouse testes. Stem Cell Rev Rep. 2020;16:992-1004.

12. Bhartiya D, Sharma D. Ovary does harbor stem cells - size of the cells matter! J Ovarian Res. 2020;13:39. https://doi.org/10.1186/s13048-020-00647-2.

13. Bhartiya D, Shaikh A, Anand S, Patel H, Kapoor S, Sriraman K, Parte S, Unni S. Endogenous, very small embryonic-like stem cells: critical review, therapeutic potential and a look ahead. Hum Reprod Update. 2016;23(1):41-76.

14. Xiao X, Chen Z, Shiota C, Prasadan K, Guo P, El-Gohary Y, et al. No evidence for $\beta$ cell neogenesis in murine adult pancreas. J Clin Invest. 2013;123:2207-17.

15. Bhartiya D, Shaikh A, Nagvenkar P, Kasiviswanathan S, Pethe P, Pawani $H$, Mohanty S, Rao SG, Zaveri K, Hinduja I. Very small embryonic-like stem cells with maximum regenerative potential get discarded during cord blood banking and bone marrow processing for autologous stem cell therapy. Stem Cells Dev. 2012;21(1):1-6.

16. Shaikh A, Nagvenkar P, Pethe P, Hinduja I, Bhartiya D. Molecular and phenotypic characterization of CD133 and SSEA4 enriched very small embryonic-like stem cells in human cord blood. Leukemia. 2015;29(9):1909-17.

17. Ratajczak MZ, Ratajczak J, Kucia M. Very small embryonic-like stem cells (VSELs). Circ Res. 2019;124(2):208-10.

18. Shaikh A, Anand S, Kapoor S, Ganguly R, Bhartiya D. Mouse bone marrow VSELs exhibit differentiation into three embryonic germ lineages and germ \& hematopoietic cells in culture. Stem Cell Rev. 2017;13(2):202-16.

19. Ratajczak J, Wysoczynski M, Zuba-Surma E, Wan W, Kucia M, Yoder MC, Ratajczak MZ. Adult murine bone marrow-derived very small embryonic-like stem cells differentiate into the hematopoietic lineage after coculture over OP9 stromal cells. Exp Hematol. 2011:39(2):225-37.

20. Anand S, Bhartiya D, Sriraman K, Mallick A. Underlying mechanisms that restore spermatogenesis on transplanting healthy niche cells in busulphan treated mouse testis. Stem Cell Rev. 2016;12(6):682-97.

21. Patel H, Bhartiya D. Testicular stem cells express follicle-stimulating hormone receptors and are directly modulated by FSH. Reprod Sci. 2016;23(11):1493-508.

22. Sriraman $K$, Bhartiya $D$, Anand $S$, Bhutda $S$. Mouse ovarian very small embryonic-like stem cells resist chemotherapy and retain ability to initiate oocyte-specific differentiation. Reprod Sci. 2015;22(7):884-903.

23. James K, Bhartiya D, Ganguly R, Kaushik A, Gala K, Singh P, Metkari SM. Gonadotropin and steroid hormones regulate pluripotent very smal embryonic-like stem cells (VSELs) in adult mouse uterine endometrium. J Ovarian Res. 2018;11(1):83. https://doi.org/10.1186/s13048-018-0454-4.

24. Bhartiya D. Clinical translation of stem cells for regenerative medicine. Circ Res. 2019;124(6):840-2
25. Kaushik A, Anand S, Bhartiya D. Altered biology of testicular VSELs and SSCS by neonatal endocrine disruption results in defective spermatogenesis, reduced fertility and tumor initiation in adult mice. Stem Cell Rev Rep. 2020; 16(5):893-908.

26. Batlle E, Clevers H. Cancer stem cells revisited. Nat Med. 2017;23(10):1124-34.

27. Tuveson D, Clevers $\mathrm{H}$. Cancer modeling meets human organoid technology. Science. 2019:364(6444):952-5.

28. Ratajczak MZ, Bujko K, Mack A, Kucia M, Ratajczak J. Cancer from the perspective of stem cells and misappropriated tissue regeneration mechanisms. Leukemia. 2018;32:2519-26.

\section{Publisher's Note}

Springer Nature remains neutral with regard to jurisdictional claims in published maps and institutional affiliations. 